\title{
Piezometric variation of the water table in the the Municipality of El- Oued, south-east Algeria
}

\author{
Zine Brahim ${ }^{1}$, Zaiz Issam ${ }^{2}$ \\ ${ }^{I}$ Department of Civil Engineering and Hydraulic, University of Kasdi Merbah, Ouargla, ALGERIA \\ ${ }^{2}$ Department of Civil Engineering and Hydraulic, University of Kasdi Merbah, Ouargla, ALGERIA \\ hydro.br@gmail.com
}

\begin{abstract}
Municipality of El-Oued has been confronted with the phenomenon of the upwelling of water for several years and without almost any cease to become more extensive each year. This phenomenon took very alarming dimensions the last twenty years. The use of the deep layers water (the Continental intercalary and the Final Complex) in an excessive way considerably increased the volume of the water input, as well as the absence of a natural discharge system for the rejections of wastewater, are the principal causes of this ecological imbalance. Contributing to the deterioration of the palm trees, the inundation of (Ghouts) causes mortal consequences at the level of environment, agriculture, the economy and the health of Municipality of El-Oued.

The piezometric variation of the water table has shown that in the areas of upwelling groundwater; correspond to piezometric depressions which has favored the accumulation and especially of the waste water.
\end{abstract}

Keywords: Piezometric Variation, Water Table, El-Oued, Depressions.

Received: 01/06/2017 - Accepted: 27/06/2017

\section{Introduction}

These Some regions such as the municipality of El-Oued are confronted with the phenomenon of the rise in surface area, groundwater for several years and which keeps growing every year. This phenomenon of the upwelling of groundwater has assumed very alarming dimensions in recent years. The use of deep water (the Terminal Complex and the Continental Intercalary) in an excessive manner has considerably increased the volume of inputs, as well as leakage from the Drinking Water Supply networks and the absence of a natural outlet for the Discharges of sewage, are the main causes of this ecological imbalance. Contributing to the decline of palm trees, the flooding of craters and depressions (Ghouts).

In this study, we looked at the level of ground water in urban and agricultural areas.

\section{The geographical situation of municipality of El-Oued}

The study area is located in the commune of ElOued, the most agglomerated commune, is the chief place of El-Oued, one of the main oases of the Algerian Northern Sahara in the Eastern Erg. It is located in the south-east of Algeria, about $700 \mathrm{~km}$ south-east of Algiers and $350 \mathrm{~km}$ west of Gabes (Tunisia), north-east of the northern Sahara. The municipality covers a total area of $79 \mathrm{~km} 2$, is limited to the north by the commune of Kouinine, to the south by the municipality of Bayadha, in the east by the commune of Trifaoui and to the West by the commune of Oued Alenda. This commune extends between the following coordinates (UTM, Clark 1880) (Figure 1):

$\mathrm{X}=298000 \mathrm{~m} ; \mathrm{Y}=3690000 \mathrm{~m}$

$\mathrm{X}=304000 \mathrm{~m} ; \mathrm{Y}=3698000 \mathrm{~m}$

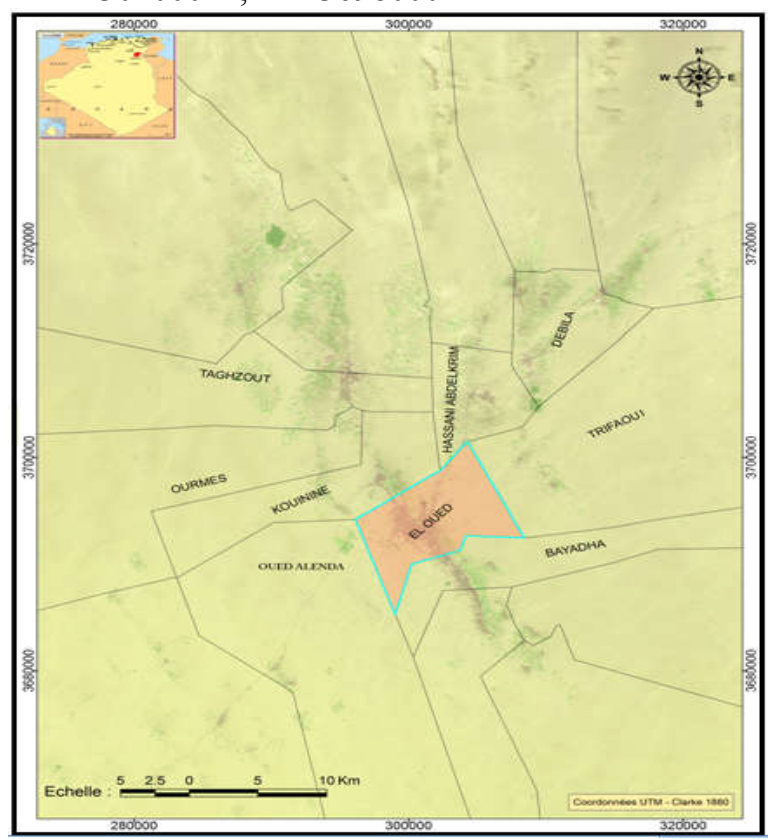

Figure 1. Geographical location of the study area. 
The valley of the souf contains a number of oases in the Grand Erg oriental, and as in most oasis in the northern Sahara, the only water resources available for irrigation are underground water tables. Those of the Souf region are contained in aquifer formations of different natures. At the regional and country levels, the authors (Baba SY, 2005, Brl-bneder, 1999, Cornet 1961, Castany 1982, Cornet and Gouscov 1952, Guendouz A, et al., 2003, UNESCO, 1972a) [1,2]. Generally distinguish three geological complexes that contain groundwater resources of thickness and hydrogeological characteristics variables.

The water table throughout the Souf rests on the argilo-gypsum floor of the upper Pontian. The aeration zone separating the surface of this water from the surface of the soil does not exceed an average depth of more than $40 \mathrm{~m}$ of non-aquifer sand [3].

\section{Digital Terrain Model of the Study Area}

The study area occupies a large part of the municipality of El Oued in which the topographic surface has been interpolated from 9892 ground leveled points for the sanitation network in the urban areas and 129 points in the non-Urban areas, ie 10021 points covering the area of a digital terrain model (Figure 2).

According to the Digital Terrain Model, this region has an average altitude of $82 \mathrm{~m}$ above mean sea level and is marked by a significant decrease from southwest to north to reach $66 \mathrm{~m}$ altitude.

The topographical features have been shown in the following table in elevation ranges (Table1).

Table 1. Distribution of elevation ranges

\begin{tabular}{ccc}
\hline Altitude range $(\mathrm{m})$ & Surface $\left(\mathrm{Km}^{2}\right)$ & Area $(\%)$ \\
\hline $64-70$ & 4.2 & 10.5 \\
$70-76$ & 15 & 37.5 \\
$76-82$ & 13 & 32.5 \\
$82-88$ & 3.6 & 9 \\
$88-94$ & 3 & 7.5 \\
$94-100$ & 1.2 & 3
\end{tabular}

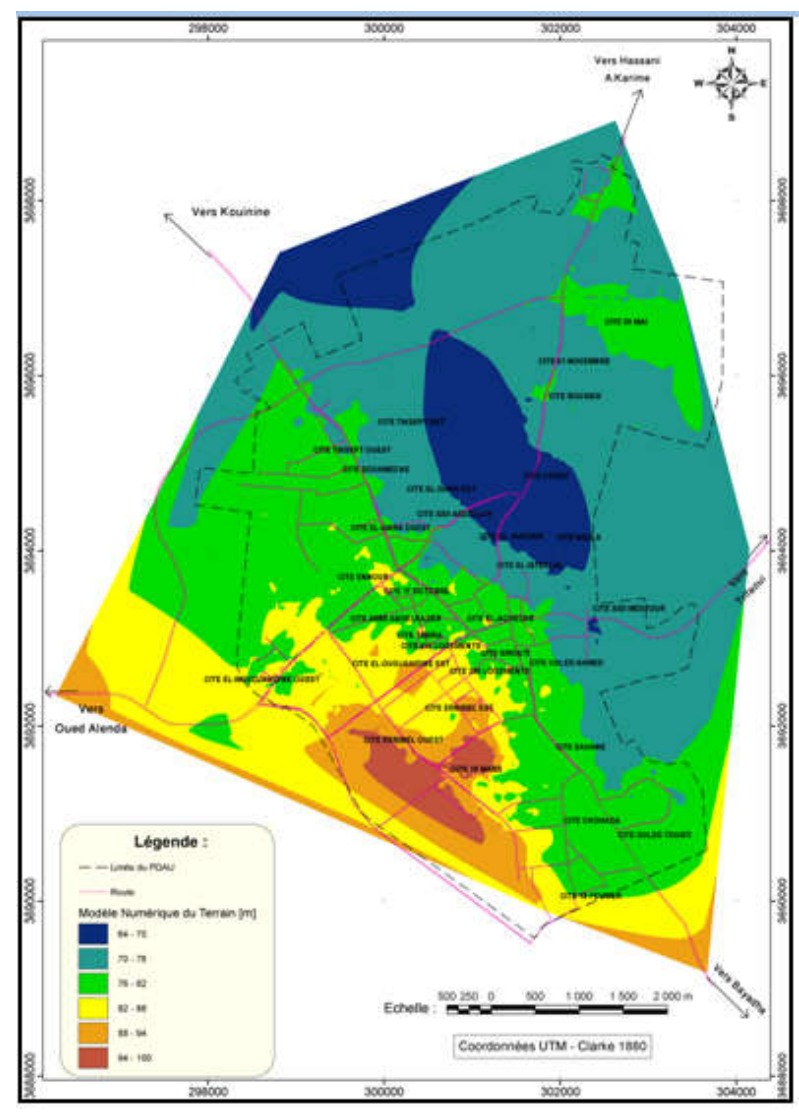

Figure 2. Digital Terrain Model of the Study Area.

The study area is characterized by two important domes in the cities of Mars 19 and Mai 8 and a depression in the cities Choot and Nezla.

\section{Piezometry of the water table of the Souf region}

IV.1. Inventory of water points

The monitoring network of the city of Oued Souf, set up in 2006 was originally composed of 62 points, spread over the city in a zone of $40 \mathrm{~km}^{2}$, the coordinates were recorded to the Global Positioning System and all the data collected were introduced into a database linked to a geographic information system (Figure 3 ).

In 2008, a companion for the measurement of groundwater piezometric levels was carried out by the National Agency of Hydraulic Resources in Mai.

In 2009, a companion was made to measure the piezometric levels of the water table in the flooded areas in January and Mai. 


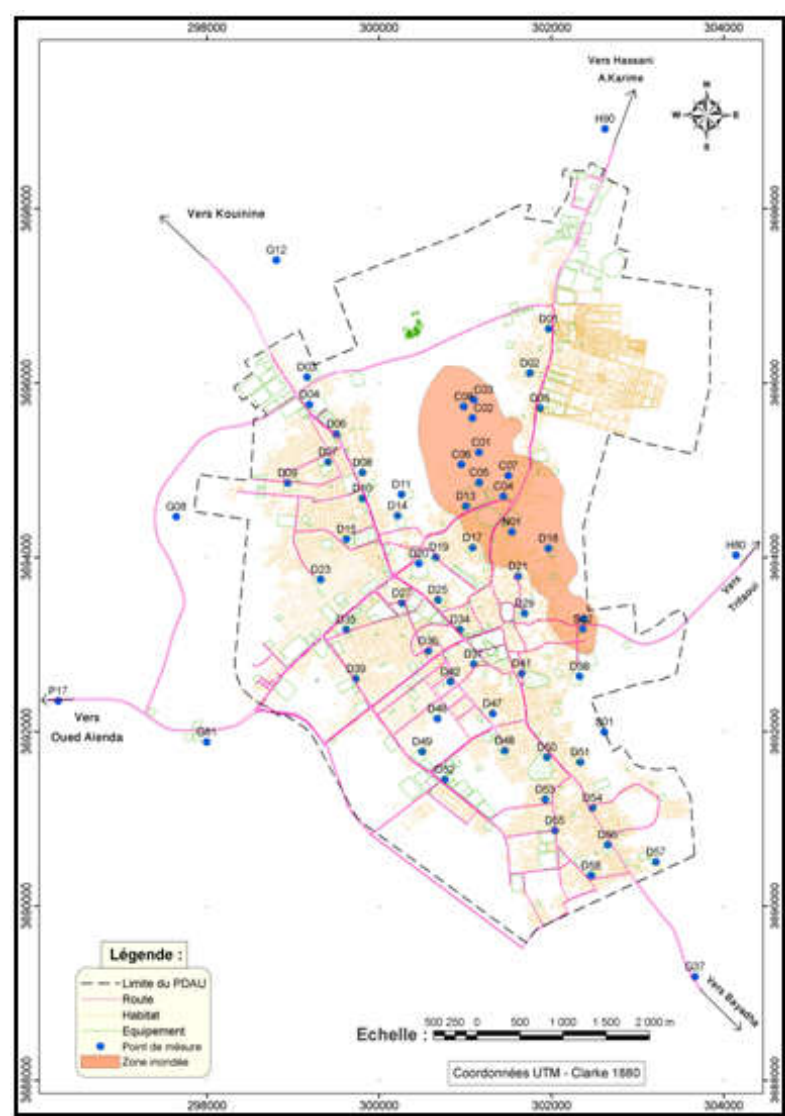

Figure 3. Network monitoring of the souf region.

\section{IV.2. The piezometry of the free water table in 2008}

The piezometric measurements carried out in Mai 2008 by the National Agency of Hydraulic Resources enabled us to establish a piezometric map (Figure 4). It is noted that the groundwater is characterized the existence of three important areas.

- Zone A1, that of the city of 19 Mars, Errimel West, Errimel East, El-Mujahideen West, El-Mujahideen East, 300 housing units, 400 housing units, Tawba, Amir Abdelkader, 17 October and Ennour A piezometric dome with an altitude ranging from $74.7 \mathrm{~m}$ to $77.7 \mathrm{~m}$.

- Zone B1, represented by the cities 08 Mai and 01 November at northeast, characterized by a piezometric dome with an altitude ranging from $67.2 \mathrm{~m}$ to $70.2 \mathrm{~m}$.

- Zone $\mathrm{C} 1$, at the center represented by the Choot city, corresponding to a major depression of an altitude ranging from $64.2 \mathrm{~m}$ to $65.7 \mathrm{~m}$, it is characterized by the rise of the surface water table (Figure 4).

We note in passing that:

- The piezometric dome corresponds to a feeding zone.

- A piezometric depression corresponds to drainage.

The water table in the town of Oued Souf has the following flow directions:

- From northeast of zone A1 to zone C1 (cited Choot).

- From the north of zone A1 to the north-west of the town near point G12.
- From the southwest of the town near the P17 piezometer to the northwest of the town near the G12 well.

- From the east of zone A1 towards the east the town near the well H80.

- From the south of zone B1 to zone C1 (quoted Choot). - A divergent flow is obtained from the piezometric dome of zone A1, from the SW to the NE and from the NE to the SW.

- There is a second flow diverging from the piezometric dome of zone B1 to NE therefore from east to west and from west to east.

- A convergence of the flows of all the senses towards zone $\mathrm{C} 1$ of the Choot.

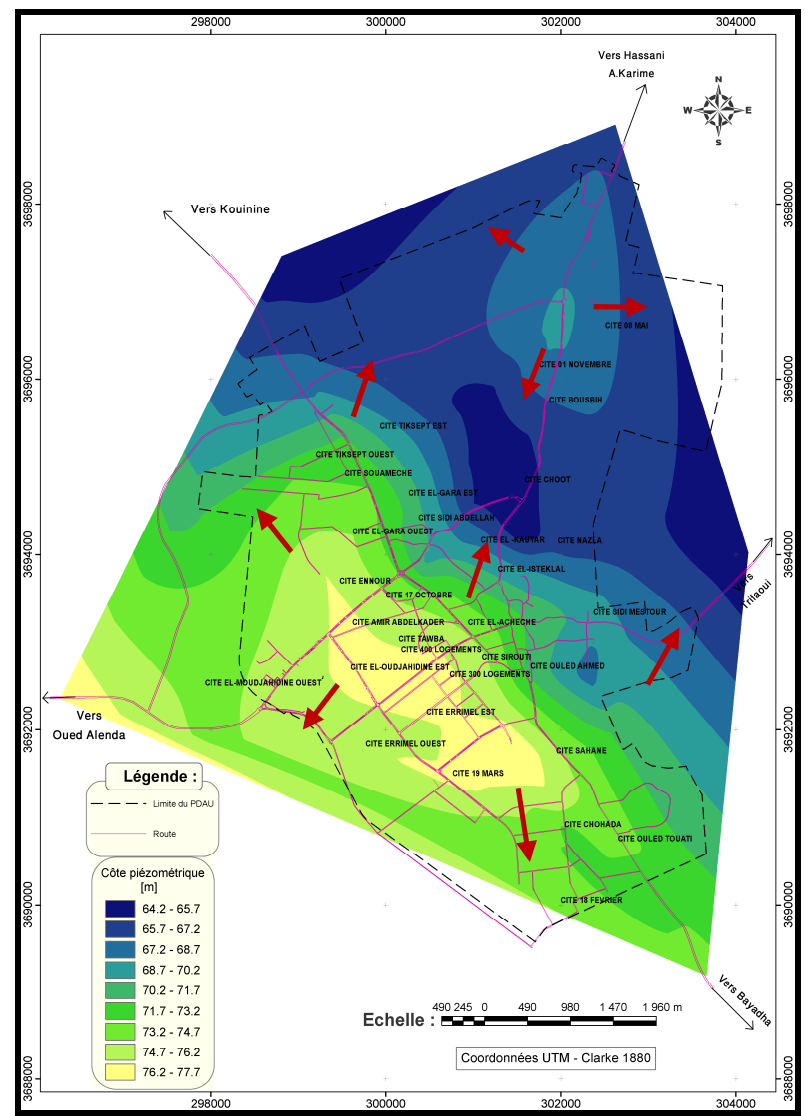

Figure 4. Piezometric map of the water table of the of Oued Souf in 2008 .

IV.3. The piezometry of the free water table in 2009

In order to follow the evolution of the water table, we made piezometric measurements in Mai 2009, which enabled us to establish a piezometric map (Figure5). We have noticed that the water table has retained the same structure as before, with a significant rise in the piezometric level.

We estimate this rise to $50000 \mathrm{~m} 3$ of water in one year. 


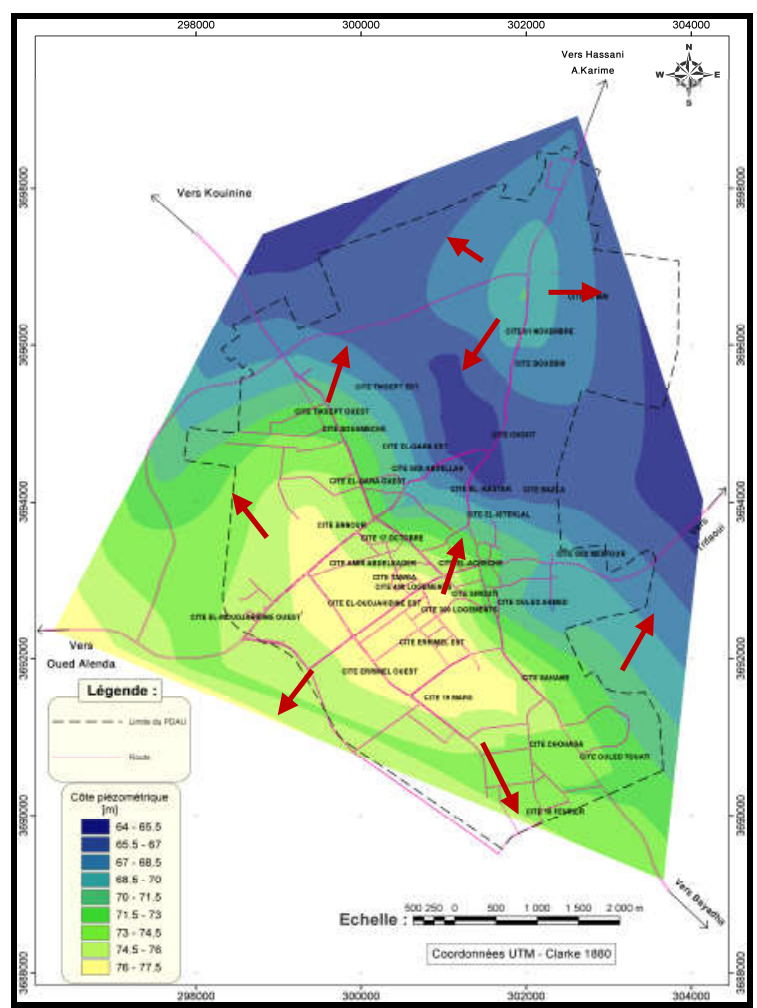

Figure. 5 Piezometric map of the water table of the of Oued Souf in 2009 .

\section{IV.4. Piezometry between 2009 and 2008}

The map of the figure below (Figure 5) shows the evolution of the piezometric level from one year to the next.

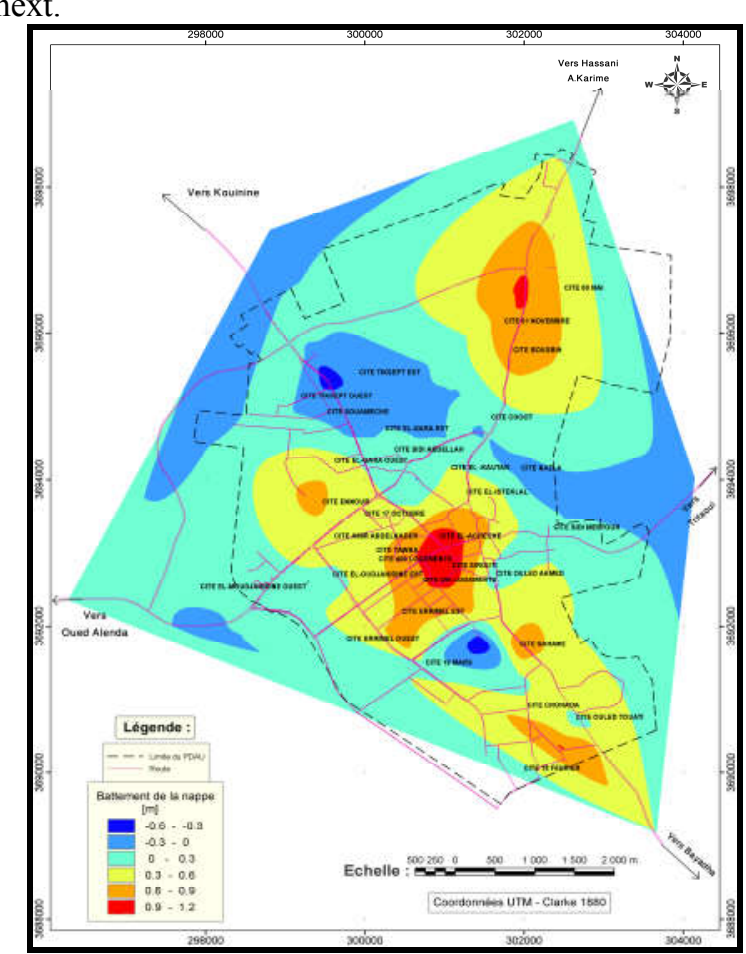

Figure. 6 Piezometric beating map between 2009 and 2008.
Between May 2009 and May 2008, a groundwater level rise of 1.2 meters was observed at the feeding zones represented by the agglomerations and a drawdown of 0.6 meters in the evaporation zones of open water surfaces ( Chott, flooded ghouts) and vegetation evapotranspiration (traditional ghout crops, irrigated crops by traditional or improved wells in the groundwater).

\section{Conclusion}

The only available water resources are underground water tables. The aquifer of the valley of the Souf is contained in formations of different nature. Feeding of the surface aquifer is ensured by the infiltration of deep CT and CI drilling waters, by urban water, by irrigation water, and by rare and low exceptional precipitation. This water table goes up in the depressions, under the agglomerations and falls in the irrigated zones.

The general direction of groundwater flow is from South West to the North East.

The piezometric maps of the city of El Oued show this situation well.

Faced with this critical situation, especially in the agglomeration areas, there are several solutions that have been proposed and that are currently being implemented to shape a new Sufi landscape.

The increase in pumped volumes and the development of Saharan agriculture have repercussions at the level of these Saharan aquifers (Terminal complex) in the form of the drying up of the sources and the weakening or losing of artesianism as in our region. This increasing exploitation is likely to lead to changes in water quality in the vulnerable zones (Salt and mineral concentrations) over the long term [4].

\section{References}

[1] M. Baba Sy, Besbes M., 2006. Holocene recharge and present recharge of the Saharan aquifers. A study by numerical modelling, Colloque international - Gestion des grands aquifères - 30 mai-1er juin 2006, Dijon, France. $\mathrm{p} 16$.

[2] A.Guendouz, A.S. Moulla, W.M. Edmunds, K. Zouari, P.Shand, A.Mamou, 20 May 2003. Hydrogéochemical and isotopic evolution of water in the Complexe Terminal aquifer in the Algerian Sahara, Hydrogeology Journal (2003). pp 485-495.

[3] A.R. Voisin, 2004. Les Souf monographie, Edition ElWalid, El Oued-Algérie. p 319.

[4] A. Miloudi, B. Remini, Water Potentiality of Sustainable Management Challenges in the Oued Souf Region, south east Algeria, International Journal of Energetica (IJECA), Vol.1 Issue.1, 2016, pp.36-39. 